Bioconjug Chem. 2016 October 19; 27(10): 2407-2417. doi:10.1021/acs.bioconjchem.6b00377.

\title{
Synthesis, in vitro and in vivo evaluation of MMP-12 selective optical probes
}

\author{
Thomas Bordenave ${ }^{\S}$, Marion Helle ${ }^{\S}$, Fabrice Beau ${ }^{\S}$, Dimitris Georgiadis ${ }^{\circ}$, Livia Tepshi§, \\ Mylène Bernes ${ }^{\S}$, Yunpeng Ye ${ }^{\#, / /}$, Laure Levenez ${ }^{\S}$, Enora Poquet ${ }^{\S}$, Hervé Nozach ${ }^{\S}$, Mahmoud \\ ${\text { Razavian\# } \#, / / \text {, Jakub Toczek } \#, / / \text {, Enrico A. Stura }{ }^{\S} \text {, Vincent Dive }}^{\S}$, Mehran M. Sadeghi $\#, / /$, and \\ Laurent Devel§,*
}

§Service d'ingénierie moléculaire des protéines (SIMOPRO), IBITECS, CEA, Université ParisSaclay, Gif/Yvette, F-91191 (France)

\#Cardiovascular Molecular Imaging Laboratory, Section of Cardiovascular Medicine and Yale Cardiovascular Research Center, Yale University School of Medicine, New Haven, CT-06511 (USA)

\author{
"Veterans Affairs Connecticut Healthcare System, West Haven, CT-06516 (USA) \\ 'Department of Chemistry, Laboratory of Organic Chemistry, University of Athens, \\ Panepistimiopolis, Zografou, Athens, 15771 (Greece)
}

\begin{abstract}
In designing new tracers consisting of a small-peptide conjugated to a reporter of comparable size, particular attention needs to be paid to the selection of the reporter group which can dictate both the in vitro and in vivo performances of the whole conjugate. In the case of fluorescent tracers, this is particularly true given the large numbers of available dye moieties differing in their structures and properties. Here, we have investigated the in vitro and in vivo properties of a novel series of MMP-12 selective probes composed of cyanine dyes varying in their structure, net charge and hydrophilic character, tethered through a linker to a potent and specific MMP-12 phosphinic pseudo peptide inhibitor. The impact of linker length has been also explored. The crystallographic structure of one tracer in complex with MMP-12 has been obtained, providing the first crystal structure of a Cy5.5-derived probe and confirming that the binding of the targeting moiety is unaffected. MMP-12 remains the tracers privileged target as attested by their affinity selectivity profile evaluated in solution towards a panel of twelve metalloproteases. In vivo assessment of four selected probes has highlighted the impact of the dye structure, but also that of the linker length on the probes blood clearance rates and their biodistributions. These experiments have also provided valuable data on the stability of the dyes moieties in vivo. This has permitted the identification of one probe, which combines favorable binding to MMP-12 in solution and on cells
\end{abstract}

\footnotetext{
*Corresponding Author: Laurent.DEVEL@ @ea.fr.

Supporting information

Synthesis and characterization of compounds 1 to 14, crystallization protocols to access to 1/hMMP-12 complex, in vitro, in vivo and on cells experiments are detailed in the supporting information.

The manuscript was written through contributions of all authors. All authors have given approval to the final version of the manuscript. The authors declare no competing financial interest.
} 
with optimized in vivo performance including blood clearance rate suitable for short-time imaging. Through this series of tracers, we have identified various critical factors modulating the tracers' in vivo behavior, both useful for the development and optimization of MMP-12 selective radiolabeled tracers and informative for the design of fluorescent probes in general.

\section{INTRODUCTION}

MMPs (Matrix Metallo Proteinases) belong to the family of zinc endopeptidase which in humans comprise 23 members. These enzymes are synthesized as latent zymogens and thus require proteolytic activation by other proteases. Active forms have been associated with normal physiological processes such as tissue remodeling, embryonic implantation, organ development and wound healing ${ }^{1}$. Because uncontrolled MMP activity could have disastrous effects on the micro-environment, the level of MMP expression, cellular localization and their proteolytic activity are tightly controlled at both transcriptional and post-transcriptional levels. In contrast, pathological processes are characterized by enhanced MMP expression and uncontrolled proteolytic activity. In this respect, active forms have been proposed to be critical actors in several pathologies such as cancer initiation and progression ${ }^{2}$, neurodegenerative disorders ${ }^{3}$, osteoarthritis and inflammatory ${ }^{4,5}$ and vascular diseases ${ }^{6}$. Although our knowledge is expanding, the precise functional role of MMP active forms, both in normal and diseased tissues remains difficult to assess. This is particularly true in pathological cases where certain MMPs participate in disease progression while others play a protective role r-11. $^{7}$.

Regarding MMP-12, the so-called macrophage elastase, its involvement in overcoming bacterial infection ${ }^{12}$, regulating antiviral immunity ${ }^{13}$ and resolving inflammation ${ }^{14}$ has been clearly demonstrated. Its therapeutic potential has been stressed from its implication in emphysema ${ }^{15}$, abdominal aortic aneurysm ${ }^{16}$ and atherosclerosis ${ }^{6}$. In this latter case, active MMP-12 has been shown to be involved in the progression, destabilization and rupture of atherosclerotic lesions, a leading cause of myocardial infarction and stroke ${ }^{17}$. Interestingly, among the 23 human MMPs, MMP-12 illustrates quite well the compartmentalization conundrum affecting several water-soluble enzymes. Indeed, this enzyme is first excreted and diffuses through the extracellular space in its zymogen form (full form at 54kDa comprising a propeptide, a catalytic domain and an additional hemopexin-like domain) that can be subsequently activated by proteolysis. The hemopexin-like domain contributes to improved MMP-12-mediated substrate catalysis ${ }^{18}$ although it is commonly shed during MMP-12 activation ${ }^{19}$. The resulting catalytic domain $(22 \mathrm{kDa})$ can remain in the extracellular space or, as recently suggested, localise near or at the cell's surface ${ }^{20,21}$. Such a pericellular localisation may be consistent with MMP-12 driven shedding of Tumour Necrosis Factor-a (TNF-a) from leukocytes in smoke-exposed lungs ${ }^{22}$. Remarkably, active forms of MMP-12 (catalytic domain) can also penetrate virus-infected cells and further translocate to the nucleus where it activates Interferon- $a$ transcription as a response to viral infection ${ }^{13}$. Interestingly in this latter case, both intracellular and extracellular MMP-12 active forms are present and possess opposite function in vivo with the extracellular form degrading the circulating Interferon-a. Such a scenario highlights the need of developing 
tools such as imaging probes able to precisely document the time, level as well as the location of MMP-12 activation in vivo.

In 2006, we reported the first highly potent and selective inhibitor of MMP-12 23 . This pseudo peptide (RXP470.1; Figure 1A), is an active site-directed reversible inhibitor with a $\mathrm{K}_{\mathrm{i}}$ of $0.26 \mathrm{nM}$ toward human MMP-12. In a mouse model of atherosclerosis, RXP470.1 has been shown to inhibit atherosclerotic plaque growth and to promote a "stable" plaque phenotype ${ }^{24}$. Remarkably, these results reproduce the phenotype observed in MMP-12 knock-out mice, suggesting that this inhibitor is able to target MMP-12 in vivo. The potential therapeutic value of this inhibitor extends to other pathological contexts 25,26 including the treatment of viral infection achieved by selectively blocking interferon- $a$ degradation by MMP-12 ${ }^{13}$. Based on these observations, we considered that RXP470.1 may also be a valuable starting template for developing probes to selectively detect MMP-12 active forms in vivo.

Molecular imaging allows the direct monitoring of the spatiotemporal distribution of molecular or cellular processes for biochemical, biological, diagnostic or therapeutic application. As the molecular targets are present in relatively low concentrations in living tissues, the imaging techniques must be highly sensitive. In this respect, radionuclide and optical imaging can be considered as the most appropriate modalities for molecular imaging due to their sensitivity and specificity for target detection. Specifically, fluorescence imaging in the near-infrared (NIR) region allows investigating the evolving pathological process at molecular level in vivo without ionizing radiation using comparatively simple and inexpensive instrumentation ${ }^{27,28}$. Furthermore, recent advances in fluorescent chemical probe development and imaging devices are pushing forwards the clinical adoption of NIRtracers in personalized medicine and image-guided surgery ${ }^{29}$. At the core of such applications is the design of the fluorescent chemical probes with optimized performances. As the reporter might have substantial influence on the overall properties of low molecularweight fluorescent tracers, particular attention should be given to its chemical structure and the way it is conjugated to the recognition element.

Here, we describe our efforts to identify RXP470-derived fluorescent probes with optimized in vitro and in vivo properties. The first probe 1, synthesized with a cyanine 5.5 (Cy5.5) NIR reporter was crystallized in complex with the MMP-12 catalytic domain. Subsequently, four probes with the same targeting moiety, but differing in their cyanine dyes and linker length, were developed and their in vitro affinity and selectivity profiles towards a panel of MMPs determined. In vivo studies were carried out on selected probes to examine their pharmacokinetics, bio-distribution and stability after intravenous administration. Finally, the most promising candidate was tested for its ability to bind and block MMP-12 activity at the surface of HeLa cells.

\section{RESULT}

\section{Design and synthesis of RXP470-derived optical probes 1}

RXP470.1 was the basis for an optical probe with a Cy5.5 fluorescent dye (compound 1, Figure 1). The probe's design was based on the crystallographic structure of RXP470.1 in 
complex with MMP- $12^{30}$. The essential roles played by the RXP470.1 hydrophobic $\mathrm{P}_{1}{ }^{\prime}$ side chain as well as the two glutamate residues at the $\mathrm{P}_{2}{ }^{\prime}$ and $\mathrm{P}_{3}{ }^{\prime}$ positions in preserving the strong affinity and selectivity in favor of MMP-12 were taken into account ${ }^{30}$. We reasoned that a chemical elongation at the $C$-terminal position, should have a negligible impact on the binding of RXP470.1 motif within the active site and that steric clashes or long-distance electrostatic effects could be prevented by moving away the fluorophore from the MMP-12 targeting moiety using a polyethylene glycol (PEG) spacer.

To prepare compound $\mathbf{1}$, the previous synthetic protocol affording the phosphinic building block 12 was substantially improved ${ }^{23}$ (Scheme $1 \mathrm{~A}$ ).

Briefly, aldehyde 6 was obtained via a Suzuki cross-coupling reaction between 4bromobenzaldehyde and 3-chlorophenylboronic acid using palladium Tetrakis as a catalyst. This aldehyde was then converted to the corresponding oxime $\mathbf{7}$ which was employed as a dipole precursor in a subsequent 1,3-dipolar cycloaddition reaction using the one-pot Huisgen protocol ${ }^{31-33}$. To this purpose, 7 was first converted into the corresponding chlorinated oxime which underwent in situ base-mediated elimination leading to the nitrile oxide dipole. This intermediate then reacted with diethyl propargylmalonate yielding the isoxazole derivative $\mathbf{8}$. This compound was subsequently converted to acrylate $\mathbf{9}$ upon mono saponification and Knoevenagel condensation with formaldehyde ${ }^{34}$. This resulting electrophile then participated in a P-Michael addition reaction with p-bromophenyl phosphinic acid ${ }^{35}$ under mild, silylating conditions to give compound $\mathbf{1 0}^{36}$. Finally, the phosphinic building block 12 was obtained in two steps after protection of the hydroxyphosphinyl moiety with an adamantyl protecting group (compound 11) followed by a saponification $\mathrm{step}^{37}$. Building block $\mathbf{1 2}$, as a racemic mixture of enantiomers, was synthesized in eight steps from commercially available precursors in an overall yield of $57 \%$.

From this block, pseudo peptide $\mathbf{1 3}$ with a free amine function in its $C$-terminal position was synthesized on solid support using standard Fmoc strategy (Scheme 1B). After cleavage from the support and RP-HPLC purification, 13 (17\% yield) was coupled with the NHSactivated Cy5.5 to yield probe $\mathbf{1}$ (60\% yield).

\section{Crystallization and molecular packing of probe 1/MMP-12 complexes}

Crystallization experiments with the catalytic domain of MMP-12 in the presence of compound 1 yielded colored crystals of various morphologies. Several X-ray diffraction data sets were collected at the synchrotron Soleil beamlines Proxima 1 and 2A to determine the positioning of the fluorophore moiety within the crystal lattice of MMP-12 molecules. In the crystallization, the MMP-12 mutant F171D reported for the crystallization of RXP470.1 $1^{30}$ and a second mutant with the additional K241A mutation were used. Both gave good quality diffracting crystals in two different polymorphs (Supporting Information, Table S1), a new monoclinic, $\mathrm{P} 2{ }_{1}$ crystal form with two molecules in the asymmetric unit, never obtained before $^{38}$, and the classical orthorhombic, $\mathrm{P} 2{ }_{1} 2{ }_{1} 2$ crystal form ${ }^{30,39,40}$ with one molecule in the asymmetric unit (Supporting Information, Table S1). The molecular packing in the two polymorphs is strongly related. The orthorhombic space group can be imposed by seeding ${ }^{41}$. 
The structure obtained from crystals grown with this technique shows some additional density for the $\mathrm{PEG}_{2}$ linker but there is no electron density for the Cy5.5 moiety of probe $\mathbf{1}$, as would be expected given the long linker and the non-specific nature of the interactions that the Cy5.5 can make with the surface of MMP-12. To obtain some electron density for the probe, due consideration was given to the hydrophobic and positively charged nature of cyanine in probe $\mathbf{1}$. To reduce non-specific hydrophobic interactions, dioxane or $\gamma$ valerolactone were added to the precipitant and the $\mathrm{pH}$ optimized to favour specific saltbridge interactions. Crystallization was carried out at low levels of supersaturation without seeding for the initial crystals. Among all the crystals tested, the new P2 1 crystal form dominates (Figure 2). The two molecules in the asymmetric unit form a dimer where the RXP470.1 targeting moiety of $\mathbf{1}$ interacts with catalytic domain of one MMP-12 molecule of the dimer, whereas the Cy5.5 part makes contact with the second MMP-12 molecule. By contrast, in the $\mathrm{P} 2{ }_{1}{ }_{1} 2$ crystal form, obtained with the MMP-12 F171D construct, the PEG linker is in poor electron density, so that it is equally likely that the Cy5.5 moiety of the probe may make an interaction with a symmetry related MMP-12 molecule positioned in a similar position to molecule B in the $\mathrm{P} 2{ }_{1}$ crystal form (Supporting Information, Figure S1A). However, it is most likely that the crystallizing unit, matches the asymmetric unit, with both the RXP470.1 and Cy5.5 portions of the probe interact with the same MMP-12 molecule (Supporting Information, Figure S1B). In both cases, the hydrophobic negatively charged Cy5.5 moiety of probe $\mathbf{1}$ tends towards the positively charged environment provided by $\operatorname{Arg} 249$, with a strong preference to stack against the guanidinium moiety (Supporting Information, Table S2). In the P2 1 crystal form one of the two Cy5.5 is better stabilized than the other. The improvement in the electron density is probably due to better positioning of one of the two benzo-indole disulfonate moieties in a groove between Lys233 and Arg249 of a symmetry related molecule. This suggests that the Cy5.5 fluorophore can influence the selection of the molecular packing, but because the contribution of the tethered Cy5.5 is minor the pathway to obtain acceptable electron density is challenging.

\section{Crystal structure of probe 1 in complex with MMP-12}

As reported previously for other MMP-12 structures ${ }^{30,39,40,42}$, the catalytic domain of MMP-12 consists of three a-helices, a twisted five- stranded $\beta$-sheet, and eight loops, with the $\mathrm{S}_{1}{ }^{\prime}$ loop forming part of the $\mathrm{S}_{1}{ }^{\prime}$ cavity (Figure $2 \mathrm{~A}$ ). The phosphinic pseudo peptide part of 1 binds to MMP-12 in a comparable manner to that observed for other phosphinic derivatives in interaction with this protease ${ }^{30}$. In this respect, the two oxygen atoms of the phosphoryl function are not placed symmetrically around the catalytic zinc ion and only one oxygen binds to this atom (Figure $2 \mathrm{~A}$ and $2 \mathrm{C}$ ). The $\mathrm{P}_{1}{ }^{\prime}, \mathrm{P}_{2}{ }^{\prime}, \mathrm{P}_{3}{ }^{\prime}$ pseudo peptide backbone interacts with the bulge-edge segment (Leu ${ }^{181}-\mathrm{N}$ and $\mathrm{Gly}^{179}-\mathrm{CO}$ ) and the upper part of the $\mathrm{S}_{1}{ }^{\prime}$ subsite ( $\mathrm{Pro}^{238}{ }_{-} \mathrm{CO}$ and $\mathrm{Tyr}^{240}-\mathrm{N}$ ) by forming three hydrogen bonds (Figure $2 \mathrm{C}$ and supporting information Table $\mathrm{S} 2$ ). The $\mathrm{P}_{1}{ }^{\prime}$ isoxazolyl side chain inserts into the $\mathrm{S}_{1}{ }^{\prime}$ cavity of MMP-12 (Figure 2A). As anticipated, the polyethylene glycol spacer and the fluorophore moiety extend beyond the $\mathrm{S}_{3}{ }^{\prime}$ region (Figure 2B). Moreover, superimposition of probe $\mathbf{1}$ / MMP-12 complex with the one of RXP470.1/MMP-12 confirms that this $\mathrm{PEG}_{2}-\mathrm{Cy} 5.5$ group does not drastically impact the general binding of the RXP470.1 targeting moiety within the active site (Figure 2D). In this way, the positioning of their long hydrophobic side chain, as well as that of their pseudo peptide backbone, matches rather well between the two 
compounds. These observations validated our structure-based design and suggested that further optical probes harbouring a similar scaffold could be developed.

\section{Synthesis of RXP470-derived optical probes 2, 3, 4 and 5}

A second set of four probes with PEG spacers of different lengths and various cyanine dyes were thus synthesized following the same synthetic route as the one described for compound 1 (Scheme 1B). Probe 2 (55\%), 3 (34\%) and 4 (62\%) with a Cyanine 5, a 6SIDCC and a $\mathrm{CW} 800$ dye respectively were isolated (Figure 1). Probe 5 with a long spacer $\left(\mathrm{PEG}_{29}\right)$ and a Cy5.5 reporter was also developed (Scheme 1B). In this case, an additional BocNH-PEG ${ }_{27}{ }^{-}$ $\mathrm{COOH}$ block was incorporated on solid support. After cleavage and purification, the resulting intermediate $\mathbf{1 4}$ (34\% yield) was coupled to the appropriate fluorescent moiety yielding probe 5 (67\%). For each probe, purity was assessed by analytical RP-HPLC, NMR and mass spectrometry. All fluorescent probes were $>95 \%$ pure.

\section{In vitro characterization}

The affinity for human MMP-12 of the RXP470.1-derived probes 1-5 was initially determined (Table 1). The addition of the $\mathrm{PEG}_{2}$ spacer and a fluorescent tag to RXP470.1 scaffold (compounds 1 to 4 ) perturbs only moderately the binding to MMP-12, but with a systematic decrease in potency. In this series, the Cy5 derivative $\mathbf{2}$ with an affinity constant of $6.7 \mathrm{nM}$ appears as the least potent compound, while probe $\mathbf{1}$ retains a potency comparable to RXP470.1 (0.9 nM/1 vs $0.26 \mathrm{nM} / \mathrm{RXP} 470.1)$. Surprisingly, increasing the spacer length between the cyanine dye and the targeting moiety $\left(1 / \mathrm{PEG}_{2}\right.$ vs $\left.5 / \mathrm{PEG}_{29}\right)$ hardly perturbs the binding to MMP-12 (0.34 nM/5 vs $0.9 \mathrm{nM} / \mathbf{1})$. In parallel, the selectivity profiles of the five probes were determined on a set of ten human MMPs. In the $\mathrm{PEG}_{2}$ series (probes $\mathbf{1}$ to $\mathbf{4}$, Figure 3), as observed for MMP-12 and in comparison with RXP470.1, the spacer connected to a fluorophore, resulted in reduced potency towards all MMPs except MMP-3, for which probe 1 showed a slight gain. More importantly in this series, the nature of the NIR dye hardly affects the probe selectivity profile. Similarly, comparison between compounds $\mathbf{1}$ and 5 showed that linker length impacts only slightly the binding to the MMPs tested. In this respect, probe $\mathbf{5}$ possesses a comparable selectivity profile to that of probe $\mathbf{1}$ (Figure 3).

Overall, probes 1 to 5 remain very potent and selective for MMP-12. These five probes were also evaluated on two other metzincines (TACE and ADAMTS-4) for which they displayed very low affinity ( $\mu \mathrm{M}$ range, Supporting Information Table S3).

The propensity of probes $1,3, \mathbf{4}$ and $\mathbf{5}$ to bind plasma proteins, particularly albumin, was also evaluated in vitro. Thus, their ability to block MMP-12 activity in presence of human serum albumin (hSA) at $5 \mu \mathrm{M}$ is reported in table 1. At this low serum albumin concentration, MMP-12 activity is not perturbed. Therefore, for any given probe, a drop in affinity towards MMP-12 reflects its propensity to bind serum albumin. RXP470.1 binds human serum albumin, as shown by the 8.5 -fold shift of Ki (Table 1).

The addition of a short linker and a Cy5.5 dye (probe 1) significantly increases such a human serum albumin binding with a remarkable 88 -fold drop in apparent Ki. Interestingly, elongation of the PEG spacer ( $\mathbf{1} v s \mathbf{5}$ ) reduces binding to serum albumin and restores the 
apparent affinity for MMP-12 to a value closer to that of RXP470.1. As illustrated by the $\mathrm{PEG}_{2}$ series (compounds $\mathbf{1}, \mathbf{3}$, and $\mathbf{4}$ ), the nature of the dye also impacts the probes ability to interact with serum albumin. In this regard, 6SIDCC and CW800 derivatives (compound $\mathbf{3}$ and 4 respectively) behave similarly and display reduced binding to human serum albumin compared to probe 1 with the Cy5.5 reporter. In view of the human serum albumin results, the binding properties of compounds $\mathbf{1}$ and $\mathbf{5}$ towards MMP-12 were further investigated in presence of mouse serum albumin $(5 \mu \mathrm{M})$ and in diluted mouse plasma (Table S4). A similar behaviour was observed for probes $\mathbf{1}$ and $\mathbf{5}$ where the latter showed reduced binding to mouse serum albumin and better availability for interacting with MMP-12 in complex media, compared to its analogue with the shorter linker.

\section{Pharmacokinetics, biodistribution and in vivo stability}

To explore the in vivo behaviour of probes $1,3,4$ and $\mathbf{5}$, these were injected into C57B black mice. Interestingly, probes $\mathbf{1}$ and $\mathbf{5}$ with the same Cy5.5 reporter, but very different linker lengths, have significantly different blood clearance profiles (Figure 4A: 1: black disks; 5: empty triangles).

Thus, probe $\mathbf{5}$ with the longer $\mathrm{PEG}_{29}$ has a lower blood residual time compared to probe $\mathbf{1}$ resulting in a marked difference in the percentage of injected dose (\%ID) remaining in the bloodstream 4 h post-injection (\%ID 1: $25.1 \pm 2.9 ; 5: 8.1 \pm 0.4$ ). On the other hand, probes 3 and 4 with 6SIDCC and CW800 dyes, respectively, have similar half-lives in blood but are cleared more rapidly than probe $\mathbf{1}$ with a Cy5.5, suggesting a substantial impact of dye structure on the probes' blood clearance rates (Figure 4A: 3: black diamonds; 4: black squares). Consequently, the \%ID remaining in the blood stream $4 \mathrm{~h}$ post-injection for these two compounds is relatively low and comparable to $\mathbf{5}(<10 \% \mathrm{ID})$. Tissue fluorescence in organs (liver, spleen, kidneys and lungs) harvested at $4 \mathrm{~h}$ post-injection was evaluated using appropriate excitation and emission wavelengths. The three Cy5.5 analogues $(\mathbf{1}, \mathbf{3}$ and $\mathbf{5})$ displayed higher fluorescence signals in the kidneys relative to the liver, indicating a preferential renal clearance of these probes (Figure 4B). Probe 4 is also cleared by the kidneys, but its uptake by the liver is not negligible (Figure 4B). Urine of mice injected with probes $\mathbf{1}, \mathbf{3}$ and $\mathbf{4}$, was subsequently analysed by liquid chromatography coupled to a mass spectrometry device. For each compound, UV detection was realized at the wavelength corresponding to the maximal absorbance of its conjugated fluorochrome. In the case of $\mathbf{1}$, the probe was detected as the major compound (Figure 4C; $\mathbf{1}$ : black disk) with some minor unidentified metabolites. Interestingly, probe $\mathbf{3}$ with the highly negatively charged Cy5.5 (6SIDCC) was recovered intact in the urine (Figure 4C; 3: black diamond). By contrast, probe 4 with the CW800 dye was also detected, but was converted into a second metabolite by about $50 \%$ (Figure 4C; 4 : empty circles). In this last case, attempts to identify this metabolite were unsuccessful.

\section{Evaluation of probe RXP470-PEG $2-6$ SIDCC on HeLa cells harbouring hMMP-12 at their surface}

Probe 3, with the most favourable properties, particularly in terms of in vivo stability, was also tested on cells presenting hMMP-12 at their surface. To install active forms of hMMP-12 conjugated to a FITC Tag (hMMP-12-FITC) artificially onto the surface of HeLa 
cells, a similar protocol to that described by Koppisetti et $\mathrm{al}^{21}$, was followed. After $15 \mathrm{~min}$ incubation at $4{ }^{\circ} \mathrm{C}$ and washing steps, the proteolytic activity of a surface-bound hMMP-12FITC was measured as the release of the internal fluorescence quenching of a linear peptide substrate (Figure 5A).

Under these conditions, incubation of probe $3\left(15 \mathrm{~min}\right.$. at $4{ }^{\circ} \mathrm{C}$ at increasing concentrations, 1 $\mathrm{nM}, 10 \mathrm{nM}$ and $100 \mathrm{nM}$ ) resulted in a graduated inhibition of the proteolytic activity (Figure $5 \mathrm{~A})$. On the basis of the activity assay, the hMMP-12 concentration can be estimated around $2 \mathrm{nM}$ and an apparent Ki around $11 \mathrm{nM}$ can be deduced. A co-localization between hMMP-12-FITC (green) and probe $\mathbf{3}$ (red) at the cell surface was observed by confocal microscopy (Figure 5B). Such an observation is in accordance with our inhibition assay and confirms that probe $\mathbf{3}$ can indeed interact with MMP-12 catalytic domains anchored at the surface of cells.

\section{DISCUSSION}

Over the last fifteen years, a large number of chemical probes devoted to the detection and monitoring of MMPs activation in vivo have been reported ${ }^{29,43,44}$. Based on their chemical structures, two main categories can be distinguished: the substrate-derived probes and the ligand-derived ones. In the first case, MMP activatable optical probes such as MMPsense680 have been used to visualize MMP activity in tumor tissue ${ }^{45}$ and in atherosclerosis ${ }^{46}$. Despite their high sensitivity and low background noise in vivo, these probes suffered from several disadvantages such as long time imaging and signal attenuation due to diffusion within the tissues. Although these issues have been partly overcome with ultrafast-acting activatable probes ${ }^{47}$ and with probes connected to cell-penetrating peptides enabling their cell penetration and thus limiting their tissue diffusion ${ }^{48}$, their ability to selectively target MMP in vivo remains questionable ${ }^{43}$. Indeed, such substrate-derived probes can be processed by other proteases present locally at much higher concentration, yielding a signal that cannot be attributed unambiguously to MMPs processing. Moreover, in pathological contexts where circulating MMP activity has been evidenced ${ }^{49-51}$, these probes may turn out to be unstable in the blood stream leading to poor target/non target contrast when imaging diseased tissues ${ }^{43}$. These stability and specificity issues can be overcome, at least in part, by MMP probes possessing an inhibitor-derived scaffold. Among the most successful candidates, RP782 and RP805 are SPECT tracers able to detect MMP active forms with high efficiency in several mouse models ${ }^{52-54}$. Although very promising, such tracers based on a panMMP inhibitor scaffold, cannot discriminate between the different MMPs and thus report on which MMP is activated in the evolving pathological process. Particularly, in the case of MMP-12, selective imaging tracers may help to clarify the function of this protease in inflammation and tissue remodeling in cardiovascular diseases as well as confirming its involvement in the pathogenesis of aneurysm ${ }^{16,55-57}$.

The optical RXP470.1-derived probes consist of a small pseudo peptide conjugated to a symmetric indocarbocyanine of comparable size. In such a situation, the physicochemical properties of the reporter dye and how it is attached to the core recognition element can substantially impact both the in vitro and in vivo performance of the probes ${ }^{29}$. The crystal structure of probe $\mathbf{1}$ in complex with MMP-12, the first X-ray crystallographic study with a 
Cy5.5 probe, shows that the overall positioning of the RXP470.1 is largely unaffected by the $C$-terminal elongation (Figure 2). In this respect, probe 1 preserves the interactions that its parent molecule RXP470.1 establishes within the MMP-12 catalytic domain (Figure 2C and 2D). This observation is corroborated by affinity measurements in solution where probe $\mathbf{1}$ exhibits a similar affinity for MMP-12 as RXP470.1, with a comparable selectivity profile (Figure 3). In the same manner, probes $\mathbf{2}, \mathbf{3}$ and $\mathbf{4}$ derived from the same pattern, and only differing in their dye nature, share similar affinity and selectivity profiles with their parent molecule (Table 1 and Figure 3). Moreover, as shown with comparable affinity selectivity profiles between probe $\mathbf{1}, \mathbf{3}$ and $\mathbf{5}$ (Figure 3), neither the chemical nature of the linker (probe 3) nor its length (probe 5) seems to impact significantly the probes binding profile in solution (Figure 3). Thus in this series of tracers, the MMP binding profile continues to be mainly ruled by the RXP470.1 motif.

On the other hand, marked differences in the in vivo properties of the probes were observed. Thus probes whose structures only differ in their dye nature $(\mathbf{1}, \mathbf{3}$, and $\mathbf{4})$, possess distinct blood residual time (Figure 4A). Such features can be partly related to probes binding to plasma proteins in general and to serum albumin in particular. Indeed, a correlation between the binding to albumin and the in vivo performance has been proposed for cyanine dyepeptide conjugates, where such a binding is mainly influenced by the hydrophilic character of cyanine core as well as its chemical structure ${ }^{58,59}$. Interestingly in our case, probe $\mathbf{1}$ with the highest binding performance to serum albumin (Table 1), presents a slower blood clearance rates compared to probes $\mathbf{3}$ and $\mathbf{4}$ with lower binding performance. The difference in serum albumin binding ability between probe $\mathbf{1}$ with a Cy5.5 and $\mathbf{3}$ with a 6SIDCC can be ascribed to a difference in hydrophilicity between the two dyes, the first containing three negative charges and the second five ${ }^{60}$. At a comparable net charge and beyond a slight difference in lipophilic character between the two compounds (see clogP in Table 1), the difference in binding observed between 1 with a Cy5.5 and $\mathbf{4}$ with a CW800 dye may be explained by the different position of the hydrophilic groups within the cyanine core, a parameter which has also been shown to affect the binding to serum albumin ${ }^{59}$. An important finding regards the impact that linker length has on the blood clearance rates of the probes (probe 1 vs 5, Figure 4A). Although the effect of branched PEG chains on in vivo half-life of pharmaceuticals is well documented ${ }^{61}$, there are only a few reports on the impact of PEG spacers and their relative length on in vivo tracer performance ${ }^{62-64}$. Unfortunately, no general rule can be drawn on the impact of the PEG spacer length, which needs to be evaluated through case-by-case experimentation. In our series of probes, we found that elongating the linker $\left(\mathrm{PEG}_{2} /\right.$ probe 1 vs $\mathrm{PEG}_{29} /$ probe 5$)$ yields to a tracer that is more rapidly cleared from the blood stream. These observations also correlate with those made in vitro. In presence of human serum albumin, probe $\mathbf{5}$ has ten times higher propensity to bind MMP-12 than its homologue, 1, with a shorter linker, a trend confirmed for mouse serum albumin and in mouse plasma (Table S4). Accordingly, in this series of probes, the blood clearance rate appears to be mainly governed by their propensity to interact with serum albumin in vivo. Furthermore, tracers such as $\mathbf{3 , 4}$ and $\mathbf{5}$ display sufficiently fast blood clearance for shorttime imaging purposes. 
The biodistribution profiles of the probes are dominated by a preferential renal clearance, which is particularly pronounced in the case of probe $\mathbf{5}$ (Figure 4B). This undoubtedly constitutes a major advantage for imaging purpose. This is rather surprising for tracers whose structures have been derived from MMP inhibitors scaffold. Indeed, despite a low molecular weight that could favor renal clearance, the hydrophobic character of the majority of these tracers, notably due to the presence within their structure of a hydrophobic $\mathrm{P}_{1}{ }^{\prime}$ side chain essential for a specific and efficient binding to MMPs, induces a predominant hepatobiliary excretion ${ }^{65-67}$. In our case, despite a rather hydrophobic $\mathrm{P}_{1}{ }^{\prime}$ side chain within RXP470.1 core, the presence of negative charges both on the targeting motif and on the dye reporter, as well as a PEG linker, confer a global hydrophilic characters to the probes resulting in a rapid and preferential renal clearance.

We also observed a marked difference between the three cyanine dyes in vivo stability. In this respect, the 6SIDCC dye appears to be the most stable, as probe $\mathbf{3}$ can be recovered intact in the urine four hours post-injection (Figure 4C). By contrast, compound 4 with a CW800 dye is partially degraded within the same period of time. Such a degradation may be explained by the labile ether linkage within the cyanine structure, which can be hydrolyzed in vivo as suggested in other series of cyanine dyes with similar structures ${ }^{68}$.

Considering its in vitro and in vivo properties, probe 3 with a 6SIDCC fluorescent reporter appeared as the most promising candidate. Nevertheless, as MMP-12 may adopt in vivo a preferential localization at the surface of cells, we also assessed the ability of this highly negatively charged tracer to interact with its main target in such a situation. In this regards, our preliminary evaluation on cells, clearly showed that such a capacity is preserved with an apparent $\mathrm{Ki}(11 \mathrm{nM})$ close to the Ki observed in vitro $(5.2 \mathrm{nM})$, suggesting a minor nonspecific component in probe $\mathbf{3}$ binding. In addition, the persistence of the fluorescence signal of probe $\mathbf{3}$ at the cell surface after several cycles of washing (see supplemental information for details), is likely related to a rather high stability of the hMMP-12/probe 3 complex. Together with a rapid blood clearance, such a slow dissociation rate $\left(\mathrm{k}_{\mathrm{off}}\right)$ for probe $\mathbf{3}$ is highly desirable in order to favor a specific signal over a non specific blood signal.

Nonetheless, probe $\mathbf{3}$ remains to be validated in several preclinical models where MMP-12 is over expressed. Particularly, since its capacity to exclude certain MMPs is reduced compared to its parent molecule (i.e. MMP-10 and MMP-13, see Table S3), this will imply to correlate its accumulation, in the target tissue, with the MMPs expression. In this respect, whether the modulation of the MMP-12 expression (i.e. by invalidation of the MMP-12 gene or blockade) results in an accumulation decrease within the tissue, this will reflect the probe 3 capacity to selectively detect MMP-12 in vivo.

In summary, RXP470.1-derived probes developed in this study may help to assess the presence of active forms of MMP-12 in preclinical models and may constitute relevant tools for biomedical research and drug development. Furthermore, the observations that we made for this series of optical probes, particularly the factors governing their in vivo pharmacokinetics and bio-distribution, will be certainly useful for developing RXP470.1derived radiolabeled tracers with optimized properties. Such tracers are under development and, could find a broad range of application particularly in cardiovascular imaging. 


\section{Supplementary Material}

Refer to Web version on PubMed Central for supplementary material.

\section{Acknowledgments}

This research was financially supported by the European FP7 program "Nanoathero"(2013-2018, Laure Levenez, EUR772309820), National Institutes of Health (Thomas Bordenave, Ye Yunpeng and Mehran M. Sadeghi: R01 HL112992, Jakub Toczek and Mehran M. Sadeghi: R01 HL114703) and Department of Veterans Affairs Merit Award (Mehran M. Sadeghi: I0-BX001750). The "Service d'ingénierie moléculaire des protéines" belongs to the Laboratory of Excellence in Research on Medication and Innovative Therapeutics (LabEx LERMIT), we would like to thank it for its financial support (Marion Helle, ANR-10-LABX-33). We are grateful to the French synchrotron SOLEIL for allocation of beam time on Proxima 1 and Proxima 2A and to Drs. Isabet, Willam Shepard and Martin Savko for assistance during data collection.

\section{References}

1. Page-McCaw A, Ewald AJ, Werb Z. Matrix metalloproteinases and the regulation of tissue remodelling. Nat Rev Mol Cell Biol. 2007; 8:221-233. [PubMed: 17318226]

2. Kessenbrock K, Plaks V, Werb Z. Matrix Metalloproteinases: Regulators of the Tumor Microenvironment. Cell. 2010; 141:52-67. [PubMed: 20371345]

3. Huntley GW. Synaptic circuit remodelling by matrix metalloproteinases in health and disease. Nat Rev Neurosci. 2012; 13:743-757. [PubMed: 23047773]

4. Hu J, Van den Steen PE, Sang QXA, Opdenakker G. Matrix metalloproteinase inhibitors as therapy for inflammatory and vascular diseases. Nat Rev Drug Discov. 2007; 6:480-498. [PubMed: 17541420]

5. Vandenbroucke RE, Libert C. Is there new hope for therapeutic matrix metalloproteinase inhibition? Nat Rev Drug Discov. 2014; 13:904-927. [PubMed: 25376097]

6. Dollery CM, Libby P. Atherosclerosis and proteinase activation. Cardiovasc Res. 2006; 69:625-635. [PubMed: 16376322]

7. Egeblad M, Werb Z. New functions for the matrix metalloproteinases in cancer progression. Nat Rev Cancer. 2002; 2:161-174. [PubMed: 11990853]

8. Johnson JL, George SJ, Newby AC, Jackson CL. Divergent effects of matrix metalloproteinases 3, 7, 9, and 12 on atherosclerotic plaque stability in mouse brachiocephalic arteries. Proc Natl Acad Sci U S A. 2005; 102:15575-15580. [PubMed: 16221765]

9. Overall CM, Kleifeld O. Validating matrix metalloproteinases as drug targets and anti-targets for cancer therapy. Nat Rev Cancer. 2006; 6:227-239. [PubMed: 16498445]

10. López-Otín C, Palavalli LH, Samuels Y. Protective roles of matrix metalloproteinases. Cell Cycle Georget Tex. 2009; 8:3657-3662.

11. Dufour A, Overall CM. Missing the target: matrix metalloproteinase antitargets in inflammation and cancer. Trends Pharmacol Sci. 2013; 34:233-242. [PubMed: 23541335]

12. Houghton AM, Hartzell WO, Robbins CS, Gomis-Rüth FX, Shapiro SD. Macrophage elastase kills bacteria within murine macrophages. Nature. 2009; 460:637-641. [PubMed: 19536155]

13. Marchant DJ, Bellac CL, Moraes TJ, Wadsworth SJ, Dufour A, Butler GS, Bilawchuk LM, Hendry RG, Robertson AG, Cheung CT, et al. A new transcriptional role for matrix metalloproteinase-12 in antiviral immunity. Nat Med. 2014; 20:493-502. [PubMed: 24784232]

14. Bellac CL, Dufour A, Krisinger MJ, Loonchanta A, Starr AE, auf dem Keller U, Lange PF, Goebeler V, Kappelhoff R, Butler GS, et al. Macrophage Matrix Metalloproteinase-12 Dampens Inflammation and Neutrophil Influx in Arthritis. Cell Rep. 2014; 9:618-632. [PubMed: 25310974]

15. Qu P, Du H, Wang X, Yan C. Matrix-metalloproteinase 12 Overexpression in Lung Epithelial Cells Plays a Key Role in Emphysema to Lung Bronchioalveolar Adenocarcinoma Transition. Cancer Res. 2009; 69:7252-7261. [PubMed: 19706765]

16. Longo GM, Buda SJ, Fiotta N, Xiong W, Griener T, Shapiro S, Baxter BT. MMP-12 has a role in abdominal aortic aneurysms in mice. Surgery. 2005; 137:457-462. [PubMed: 15800495] 
17. Arbustini E, Dal B, Morbini P, Burke A, Bocciarelli M, Specchia G, Virmani R. Plaque erosion is a major substrate for coronary thrombosis in acute myocardial infarction. Heart. 1999; 82:269-272. [PubMed: 10455073]

18. Lamort AS, Gravier R, Laffitte A, Juliano L, Zani ML, Moreau T. New insights into the substrate specificity of macrophage elastase MMP-12. Biol Chem. 2016; 397:469-484. [PubMed: 26760307]

19. Gronski TJ, Martin RL, Kobayashi DK, Walsh BC, Holman MC, Huber M, Wart HEV, Shapiro SD. Hydrolysis of a Broad Spectrum of Extracellular Matrix Proteins by Human Macrophage Elastase. J Biol Chem. 1997; 272:12189-12194. [PubMed: 9115292]

20. Cobos-Correa A, Trojanek JB, Diemer S, Mall MA, Schultz C. Membrane-bound FRET probe visualizes MMP12 activity in pulmonary inflammation. Nat Chem Biol. 2009; 5:628-630. [PubMed: 19648933]

21. Koppisetti RK, Fulcher YG, Jurkevich A, Prior SH, Xu J, Lenoir M, Overduin M, Van Doren SR. Ambidextrous Binding of Cell and Membrane Bilayers by Soluble Matrix Metalloproteinase- 12 . Nat Commun. 2014; 5:5552. [PubMed: 25412686]

22. Churg A, Wang RD, Tai H, Wang X, Xie C, Dai J, Shapiro SD, Wright JL. Macrophage Metalloelastase Mediates Acute Cigarette Smoke-induced Inflammation via Tumor Necrosis Factor-a Release. Am J Respir Crit Care Med. 2003; 167:1083-1089. [PubMed: 12522030]

23. Devel L, Rogakos V, David A, Makaritis A, Beau F, Cuniasse P, Yiotakis A, Dive V. Development of Selective Inhibitors and Substrate of Matrix Metalloproteinase-12. J Biol Chem. 2006; 281:11152-11160. [PubMed: 16481329]

24. Johnson JL, Devel L, Czarny B, George SJ, Jackson CL, Rogakos V, Beau F, Yiotakis A, Newby AC, Dive V. A Selective Matrix Metalloproteinase-12 Inhibitor Retards Atherosclerotic Plaque Development in Apolipoprotein E-Knockout Mice. Arterioscler Thromb Vasc Biol. 2011; 31:528535. [PubMed: 21212406]

25. Lim NH, Meinjohanns E, Bou-Gharios G, Gompels LL, Nuti E, Rossello A, Devel L, Dive V, Meldal M, Nagase H. In Vivo Imaging of Matrix Metalloproteinase 12 and Matrix Metalloproteinase 13 Activities in the Mouse Model of Collagen-Induced Arthritis. Arthritis Rheumatol. 2014; 66:589-598. [PubMed: 24574219]

26. Iyer RP, Patterson NL, Zouein FA, Ma Y, Dive V, de Castro Brás LE, Lindsey ML. Early Matrix Metalloproteinase-12 Inhibition Worsens Post-Myocardial Infarction Cardiac Dysfunction by Delaying Inflammation Resolution. Int J Cardiol. 2015; 185:198-208. [PubMed: 25797678]

27. Berezin MY, Achilefu S. Fluorescence Lifetime Measurements and Biological Imaging. Chem Rev. 2010; 110:2641-2684. [PubMed: 20356094]

28. Hilderbrand SA, Weissleder R. Near-infrared fluorescence: application to in vivo molecular imaging. Curr Opin Chem Biol. 2010; 14:71-79. [PubMed: 19879798]

29. Garland M, Yim JJ, Bogyo M. A Bright Future for Precision Medicine: Advances in Fluorescent Chemical Probe Design and Their Clinical Application. Cell Chem Biol. 2016; 23:122-136. [PubMed: 26933740]

30. Czarny B, Stura EA, Devel L, Vera L, Cassar-Lajeunesse E, Beau F, Calderone V, Fragai M, Luchinat C, Dive V. Molecular determinants of a selective matrix metalloprotease-12 inhibitor: insights from crystallography and thermodynamic studies. J Med Chem. 2013; 56:1149-1159. [PubMed: 23343195]

31. Christl M, Huisgen R. 1,3-Dipolare Cycloadditionen, 74. Orientierungsphänomene bei Cycloadditionen aliphatischer und aromatischer Nitriloxide an $\alpha, \beta$-ungesättigte Carbonester2). Chem Ber. 1973; 106:3345-3367.

32. Liu KC, Shelton BR, Howe RK. A particularly convenient preparation of benzohydroximinoyl chlorides (nitrile oxide precursors). J Org Chem. 1980; 45:3916-3918.

33. Erik Larsen K, Torssell KBG. An improved procedure for the preparation of 2-isoxazolines. Tetrahedron. 1984; 40:2985-2988.

34. Kummer DA, Chain WJ, Morales MR, Quiroga O, Myers AG. Stereocontrolled Alkylative Construction of Quaternary Carbon Centers. J Am Chem Soc. 2008; 130:13231-13233. [PubMed: 18788739] 
35. Montchamp JL, Dumond YR. Synthesis of Monosubstituted Phosphinic Acids: PalladiumCatalyzed Cross-Coupling Reactions of Anilinium Hypophosphite. J Am Chem Soc. 2001; 123:510-511.

36. Georgiadis D, Matziari M, Yiotakis A. A highly efficient method for the preparation of phosphinic pseudodipeptidic blocks suitably protected for solid-phase peptide synthesis. Tetrahedron. 2001; 57:3471-3478.

37. Yiotakis A, Vassiliou S, Jiráček J, Dive V. Protection of the Hydroxyphosphinyl Function of Phosphinic Dipeptides by Adamantyl. Application to the Solid-Phase Synthesis of Phosphinic Peptides. J Org Chem. 1996; 61:6601-6605. [PubMed: 11667528]

38. Vera L, Antoni C, Devel L, Czarny B, Cassar-Lajeunesse E, Rossello A, Dive V, Stura EA. Screening Using Polymorphs for the Crystallization of Protein-Ligand Complexes. Cryst Growth Des. 2013; 13:1878-1888.

39. Bertini I, Calderone V, Cosenza M, Fragai M, Lee YM, Luchinat C, Mangani S, Terni B, Turano P. Conformational variability of matrix metalloproteinases: Beyond a single 3D structure. Proc Natl Acad Sci U S A. 2005; 102:5334-5339. [PubMed: 15809432]

40. Devel L, Garcia S, Czarny B, Beau F, Lajeunesse E, Vera L, Georgiadis D, Stura E, Dive V. Insights from Selective Non-phosphinic Inhibitors of MMP-12 Tailored to Fit with an S1' Loop Canonical Conformation. J Biol Chem. 2010; 285:35900-35909. [PubMed: 20817735]

41. Stura EA, Wilson IA. Applications of the streak seeding technique in protein crystallization. J Cryst Growth. 1991; 110:270-282.

42. Devel L, Beau F, Amoura M, Vera L, Cassar-Lajeunesse E, Garcia S, Czarny B, Stura EA, Dive V. Simple Pseudo-dipeptides with a P2' Glutamate. J Biol Chem. 2012; 287:26647-26656. [PubMed: 22689580]

43. Lebel R, Lepage M. A comprehensive review on controls in molecular imaging: lessons from MMP-2 imaging. Contrast Media Mol Imaging. 2014; 9:187-210. [PubMed: 24700747]

44. Matusiak N, Waarde A, Bischoff R, Oltenfreiter R, van Wiele C, Dierckx R, Elsinga P. Probes for Non-invasive Matrix Metalloproteinase-targeted Imaging with PET and SPECT. Curr Pharm Des. 2013; 19:4647-4672. [PubMed: 23339739]

45. Bremer C, Tung $\mathrm{CH}$, Weissleder R. In vivo molecular target assessment of matrix metalloproteinase inhibition. Nat Med. 2001; 7:743-748. [PubMed: 11385514]

46. Deguchi J, Aikawa M, Tung CH, Aikawa E, Kim DE, Ntziachristos V, Weissleder R, Libby P. Inflammation in Atherosclerosis Visualizing Matrix Metalloproteinase Action in Macrophages In Vivo. Circulation. 2006; 114:55-62. [PubMed: 16801460]

47. Zhu L, Xie J, Swierczewska M, Zhang F, Quan Q, Ma Y, Fang X, Kim K, Lee S, Chen X. RealTime Video Imaging of Protease Expression In Vivo. Theranostics. 2011; 1:18-27. [PubMed: 21461134]

48. Jiang T, Olson ES, Nguyen QT, Roy M, Jennings PA, Tsien RY. Tumor imaging by means of proteolytic activation of cell-penetrating peptides. Proc Natl Acad Sci U S A. 2004; 101:1786717872. [PubMed: 15601762]

49. Roy R, Yang J, Moses MA. Matrix Metalloproteinases As Novel Biomarkers and Potential Therapeutic Targets in Human Cancer. J Clin Oncol. 2009; 27:5287-5297. [PubMed: 19738110]

50. Hadler-Olsen E, Winberg JO, Uhlin-Hansen L. Matrix metalloproteinases in cancer: their value as diagnostic and prognostic markers and therapeutic targets. Tumor Biol. 2013; 34:2041-2051.

51. Goncalves I, Bengtsson E, Colhoun HM, Shore AC, Palombo C, Natali A, Edsfeldt A, Dunér P, Fredrikson GN, Björkbacka H, et al. Elevated Plasma Levels of MMP-12 Are Associated With Atherosclerotic Burden and Symptomatic Cardiovascular Disease in Subjects With Type 2 Diabetes. Arterioscler Thromb Vasc Biol. 2015; 35:1723-1731. [PubMed: 25953645]

52. Zhang J, Nie L, Razavian M, Ahmed M, Dobrucki LW, Asadi A, Edwards DS, Azure M, Sinusas AJ, Sadeghi MM. Molecular Imaging of Activated Matrix Metalloproteinases in Vascular Remodeling. Circulation. 2008; 118:1953-1960. [PubMed: 18936327]

53. Razavian M, Tavakoli S, Zhang J, Nie L, Dobrucki LW, Sinusas AJ, Azure M, Robinson S, Sadeghi MM. Atherosclerosis Plaque Heterogeneity and Response to Therapy Detected by in vivo Molecular Imaging of Matrix Metalloproteinase Activation. J Nucl Med Off Publ Soc Nucl Med. 2011; 52:1795-1802. 
54. Golestani R, Razavian M, Nie L, Zhang J, Jung J-J, Ye Y, de Roo M, Hilgerink K, Liu C, Robinson $\mathrm{SP}$, et al. Imaging vessel wall biology to predict outcome in abdominal aortic aneurysm. Circ Cardiovasc Imaging. 2015:8.

55. Curci JA, Liao S, Huffman MD, Shapiro SD, Thompson RW. Expression and localization of macrophage elastase (matrix metalloproteinase-12) in abdominal aortic aneurysms. J Clin Invest. 1998; 102:1900-1910. [PubMed: 9835614]

56. Pyo R, Lee JK, Shipley JM, Curci JA, Mao D, Ziporin SJ, Ennis TL, Shapiro SD, Senior RM, Thompson RW. Targeted gene disruption of matrix metalloproteinase-9 (gelatinase B) suppresses development of experimental abdominal aortic aneurysms. J Clin Invest. 2000; 105:1641-1649. [PubMed: 10841523]

57. Wang Y, Ait-Oufella H, Herbin O, Bonnin P, Ramkhelawon B, Taleb S, Huang J, Offenstadt G, Combadière C, Rénia L, et al. TGF- $\beta$ activity protects against inflammatory aortic aneurysm progression and complications in angiotensin II-infused mice. J Clin Invest. 2010; 120:422-432. [PubMed: 20101093]

58. Ye Y, Chen X. Integrin Targeting for Tumor Optical Imaging. Theranostics. 2011; 1:102-126. [PubMed: 21546996]

59. Berezin MY, Guo K, Akers W, Livingston J, Solomon M, Lee H, Liang K, Agee A, Achilefu S. Rational approach to select small peptide molecular probes labeled with fluorescent cyanine dyes for in vivo optical imaging. Biochemistry (Mosc). 2011; 50:2691-2700.

60. Pauli J, Licha K, Berkemeyer J, Grabolle M, Spieles M, Wegner N, Welker P, Resch-Genger U. New fluorescent labels with tunable hydrophilicity for the rational design of bright optical probes for molecular imaging. Bioconjug Chem. 2013; 24:1174-1185. [PubMed: 23758616]

61. Harris JM, Chess RB. Effect of pegylation on pharmaceuticals. Nat Rev Drug Discov. 2003; 2:214-221. [PubMed: 12612647]

62. Breyholz HJ, Wagner S, Faust A, Riemann B, Höltke C, Hermann S, Schober O, Schäfers M, Kopka K. Radiofluorinated Pyrimidine-2,4,6-triones as Molecular Probes for Noninvasive MMPTargeted Imaging. ChemMedChem. 2010; 5:777-789. [PubMed: 20373323]

63. Jamous M, Tamma ML, Gourni E, Waser B, Reubi JC, Maecke HR, Mansi R. PEG spacers of different length influence the biological profile of bombesin-based radiolabeled antagonists. Nucl Med Biol. 2014; 41:464-470. [PubMed: 24780298]

64. André M, Besse S, Chezal JM, Mounetou E. PEGylation enhances the tumor selectivity of melanoma-targeted conjugates. Org Biomol Chem. 2014; 13:388-397. [PubMed: 25363288]

65. Wagner S, Breyholz HJ, Law MP, Faust A, Höltke C, Schröer S, Haufe G, Levkau B, Schober O, Schäfers $\mathrm{M}$, et al. Novel fluorinated derivatives of the broad-spectrum MMP inhibitors Nhydroxy-2(R)-[[(4-methoxyphenyl)sulfonyl](benzyl)- and (3-picolyl)-amino]-3-methylbutanamide as potential tools for the molecular imaging of activated MMPs with PET. J Med Chem. 2007; 50:5752-5764. [PubMed: 17956082]

66. Keller U, auf dem, Bellac CL, Li Y, Lou Y, Lange PF, Ting R, Harwig C, Kappelhoff R, Dedhar S, Adam, et al. Novel Matrix Metalloproteinase Inhibitor [18F]Marimastat-Aryltrifluoroborate as a Probe for In vivo Positron Emission Tomography Imaging in Cancer. Cancer Res. 2010; 70:75627569. [PubMed: 20729277]

67. Casalini F, Fugazza L, Esposito G, Cabella C, Brioschi C, Cordaro A, D’Angeli L, Bartoli A, Filannino AM, Gringeri CV, et al. Synthesis and preliminary evaluation in tumor bearing mice of new (18)F-labeled arylsulfone matrix metalloproteinase inhibitors as tracers for positron emission tomography. J Med Chem. 2013; 56:2676-2689. [PubMed: 23458498]

68. Su D, Teoh CL, Samanta A, Kang NY, Park SJ, Chang YT. The development of a highly photostable and chemically stable zwitterionic near-infrared dye for imaging applications. Chem Commun. 2015; 51:3989-3992. 

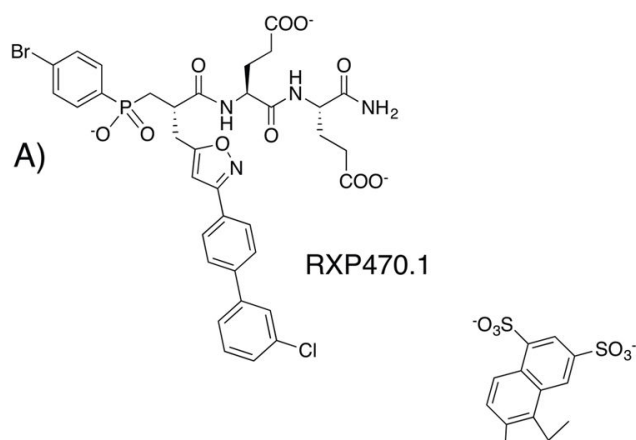

$\mathrm{R}=$

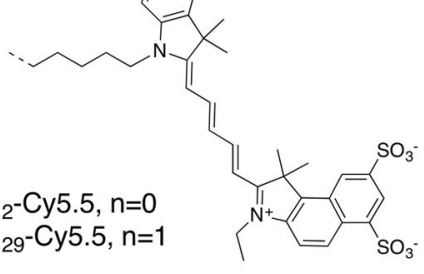

1-RXP470-PEG ${ }_{2}-\mathrm{Cy} 5.5, \mathrm{n}=0$ 5-RXP470-PEG ${ }_{29}-$ Cy5.5, $n=1$

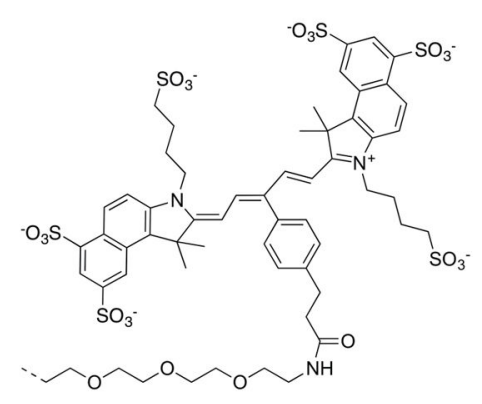

3-RXP470-PEG 4 -6S-IDCC, $n=0$
B)

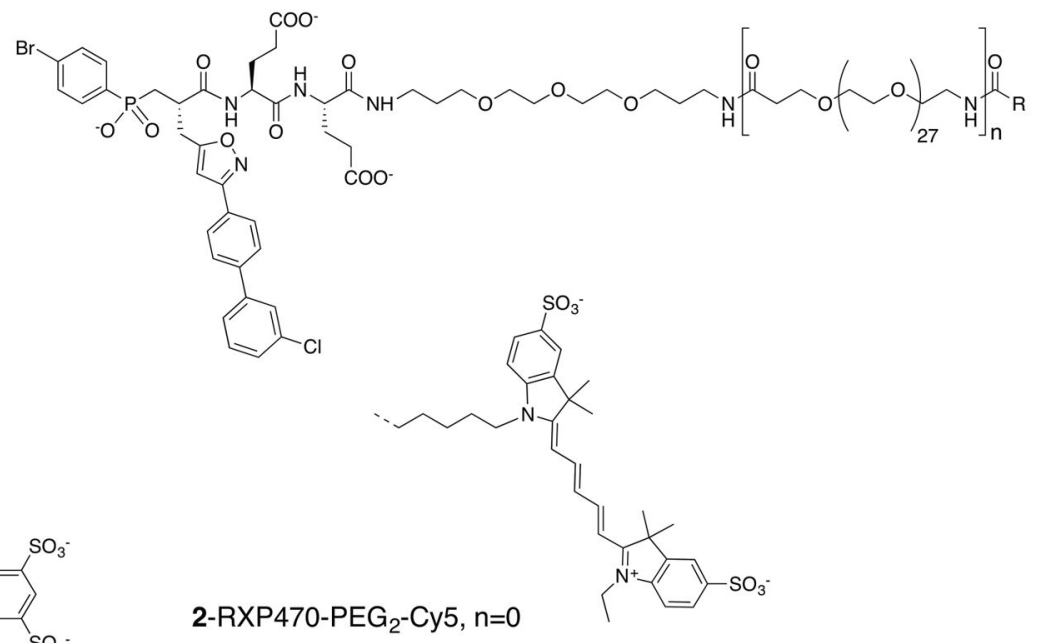

4-RXP470-PEG $2-C W 800, n=0$

Figure 1.

Chemical structure of RXP470-derived probes 1 to 5. A) Chemical structure of parent molecule RXP470.1. B) Chemical structures of RXP470.1-derived optical probes 1-5 which consist of a recognition element (RXP470.1 motif), a PEG linker of variable size ( $\mathrm{PEG}_{2}$ or $\mathrm{PEG}_{29}$ ) and carbo cyanine reporters of different structure. 


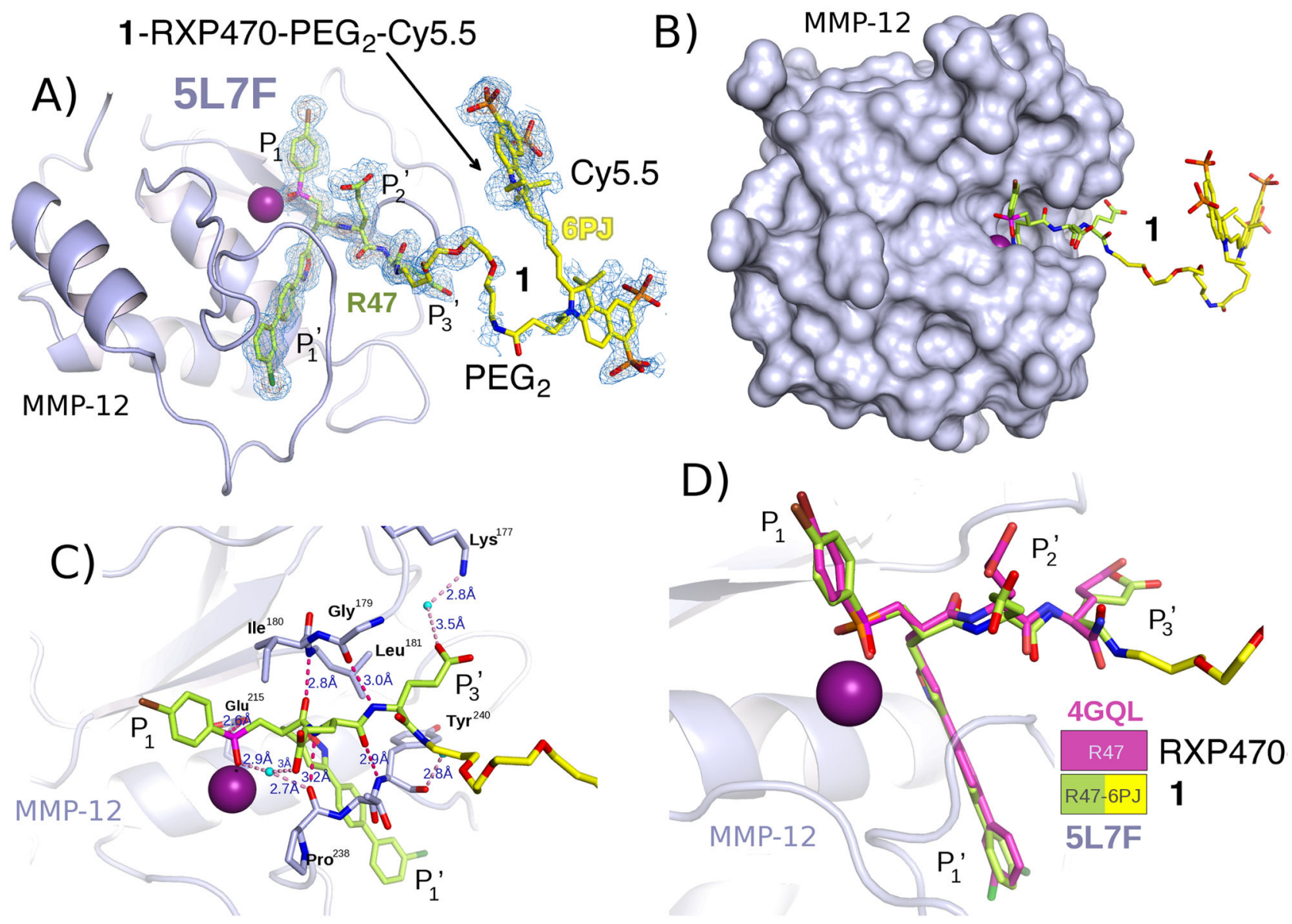

Figure 2.

Crystal structure of probe 1 in complex with hMMP-12 catalytic domain (PDB code: 5L7F) (A) Compound $\mathbf{1}$ is bound to the MMP-12 active site. Carbon atoms of $\mathbf{1}$ are shown as sticks coloured in yellow and the electron density is shown in blue. The catalytic zinc ion is in magenta. Positions $\mathrm{P}_{1}, \mathrm{P}_{1}{ }^{\prime}, \mathrm{P}_{2}{ }^{\prime}$ and $\mathrm{P}_{3}{ }^{\prime}$ along the pseudo peptide sequence are specified. (B) For probe 1/hMMP-12 complex, the hMMP-12 is shown in surface representation (C) Zoom on the RXP470.1 targeting motif within the hMMP-12 active site. The hydrogen bonds are indicated in red dotted lines and the distances given in Ångstrom. (D) Superimposition of RXP470.1 (PDB code: 4GQL) and probe 1 targeting moiety (PDB code: 5L7F; this work) within hMMP-12 active site. Carbon atoms of the RXP470.1 parent molecule are shown in pink while those of probe $\mathbf{1}$ are in yellow 


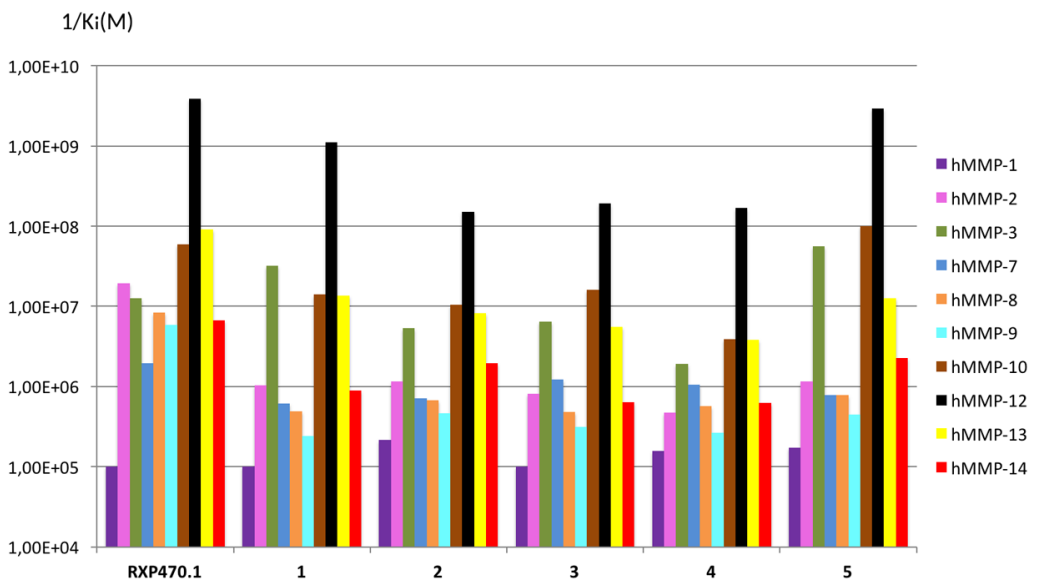

Figure 3.

Comparison of affinity selectivity profiles between RXP470.1 and probes 1-5 towards a panel of ten human MMPs identified by the color code on right of the figure. $\mathrm{Ki}(\mathrm{M})$ values were determined in $50 \mathrm{mM}$ Tris- $\mathrm{HCl}$ buffer, $\mathrm{pH} 6.8$ with $10 \mathrm{mM} \mathrm{CaCl}_{2}$ at $25^{\circ} \mathrm{C}$. Since the $1 / \mathrm{Ki}$ values are reported in logarithm scale, the error bars are not included, for standard deviations on each value, refer to Table S3. 
A)

\section{C)}

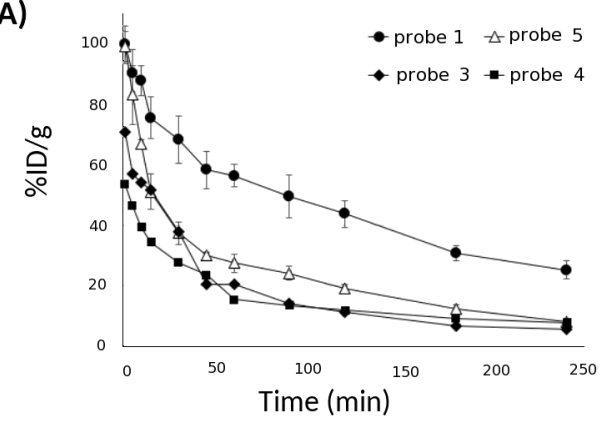

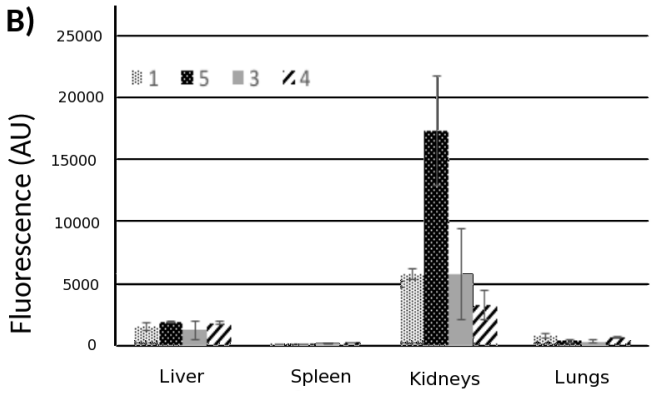
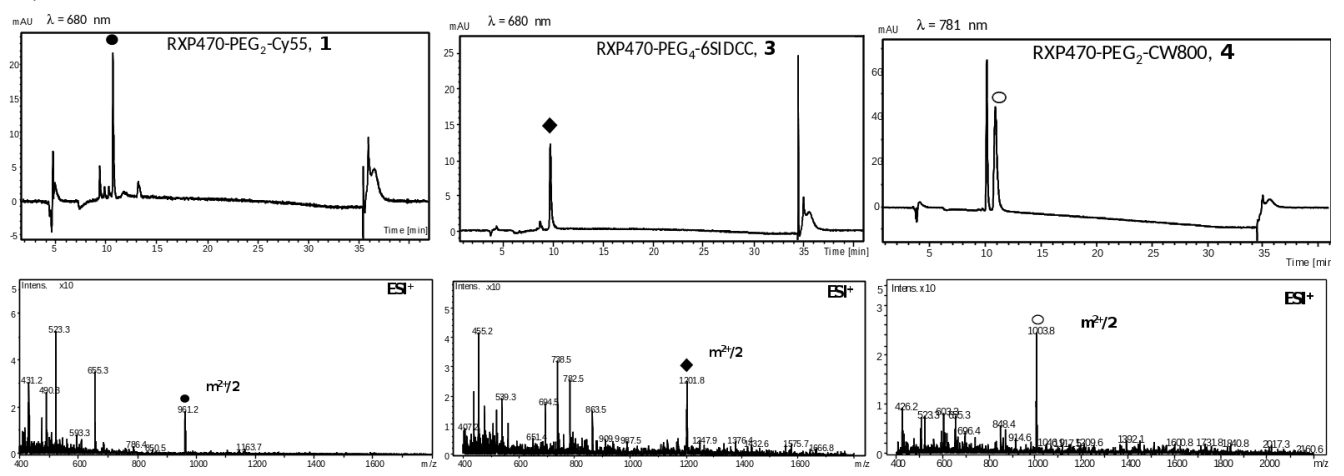

Figure 4.

Blood clearance profiles, biodistribution and urine analysis for probes $\mathbf{1 , 3}, \mathbf{4}$ and $\mathbf{5}$ in C57BL/6 ( $\mathrm{n}=3$ for each probes, $1 \mathrm{nmol}$ injected). (A) Comparison of blood clearance rates between the four probes (1: black circles, 3: black diamonds, 4: black squares and 5: empty triangles). (B) Biodistribution and fluorescence intensity patterns observed for probes 1, 3, 4 and $\mathbf{5}$ in liver, spleen, kidneys and lungs harvested $4 \mathrm{~h}$ after injection. Fluorescence is expressed as arbitrary units (AU). (C) Analyses by LC/MS of mouse urines at $4 \mathrm{~h}$ after injection in the case of probes $\mathbf{1}, 3$ and 4 . 


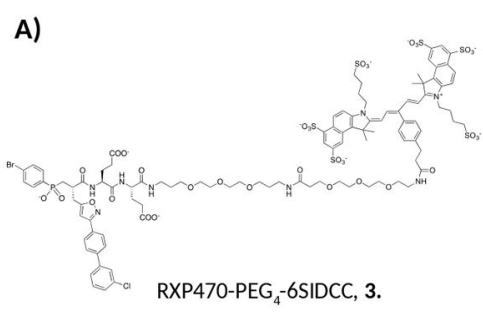

B)

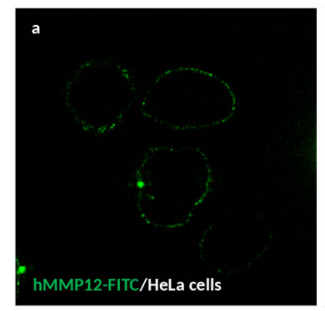

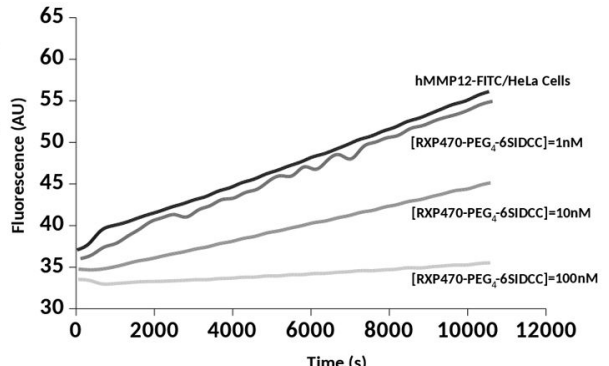

Time (s)

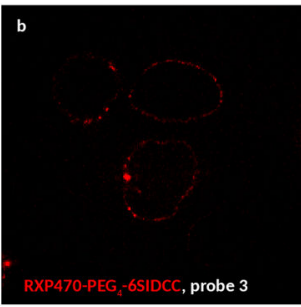

Figure 5.

Evaluation of probe 3 binding to hMMP-12-FITC anchored at the HeLa cells surface. (A) hMMP-12-FITC activity was assayed at $25^{\circ} \mathrm{C}$ in presence of a fluorogenic substrate (McaGluProGluLeuGluGluDpa) at $4 \mu \mathrm{M}$. Probe 3 at three different concentrations $(1 \mathrm{nM}, 10 \mathrm{nM}$ and $100 \mathrm{nM}$ ) was incubated at $4^{\circ} \mathrm{C}$ for $15 \mathrm{~min}$ before measuring the activity during $30 \mathrm{~min}$ at $25^{\circ} \mathrm{C}$. (B) Confocal microscopy of HeLa cells incubated with hMMP-12-FITC (green colour) and probe 3 (red colour). Blue $(491 \mathrm{~nm})$ and red $(642 \mathrm{~nm})$ lasers were used for excitation of hMMP-12-FITC and probe 3 with a Cy5.5-6SIDCC dye respectively. Bandpass filters of 525/45 nm and 692/40 nm allowed the detection of FITC and Cy5.5-6SIDCC respectively. 


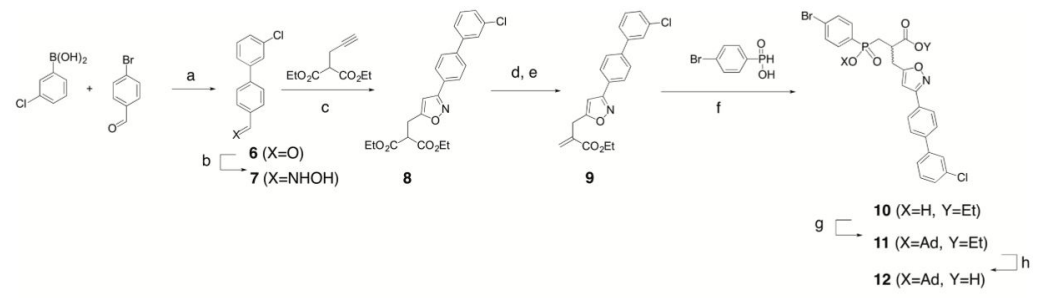

Reagents and conditions: (a) $2.5 \% \mathrm{Pd}\left(\mathrm{PPh}_{3}\right)_{4}, \mathrm{~K}_{2} \mathrm{CO}_{33}$, toluene, reflux, $24 \mathrm{~h}, 94 \%$; (b) $\mathrm{H}_{2} \mathrm{NOH} \cdot \mathrm{HCl}$, pyridine, EtOH, reflux, $3 \mathrm{~h}, 98 \%$; (c) $\mathrm{NCS}$, pyridine,

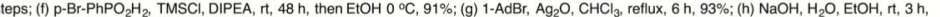

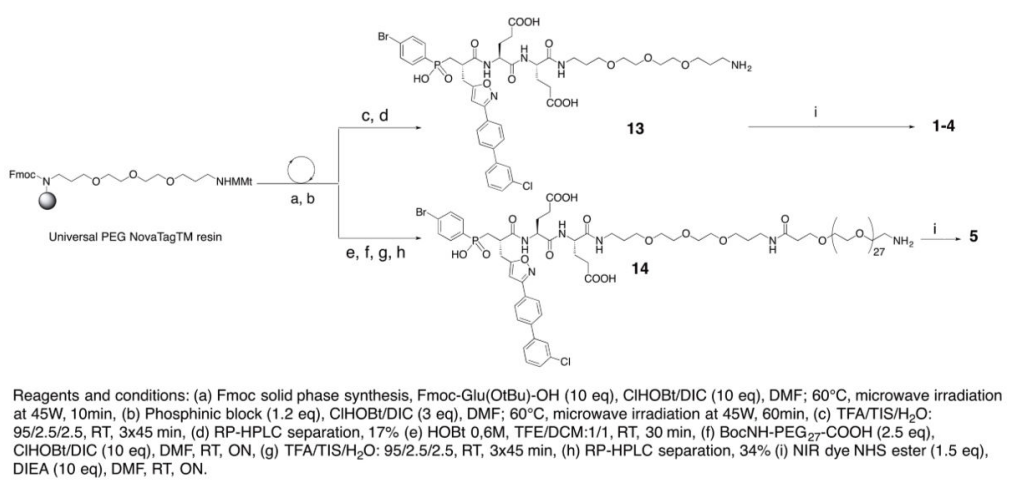

Scheme 1.

Scheme 1A Chemical pathway to access phosphinic building block 12, Scheme 1B: Synthetic route to access to fluorescent probes 1-5. 


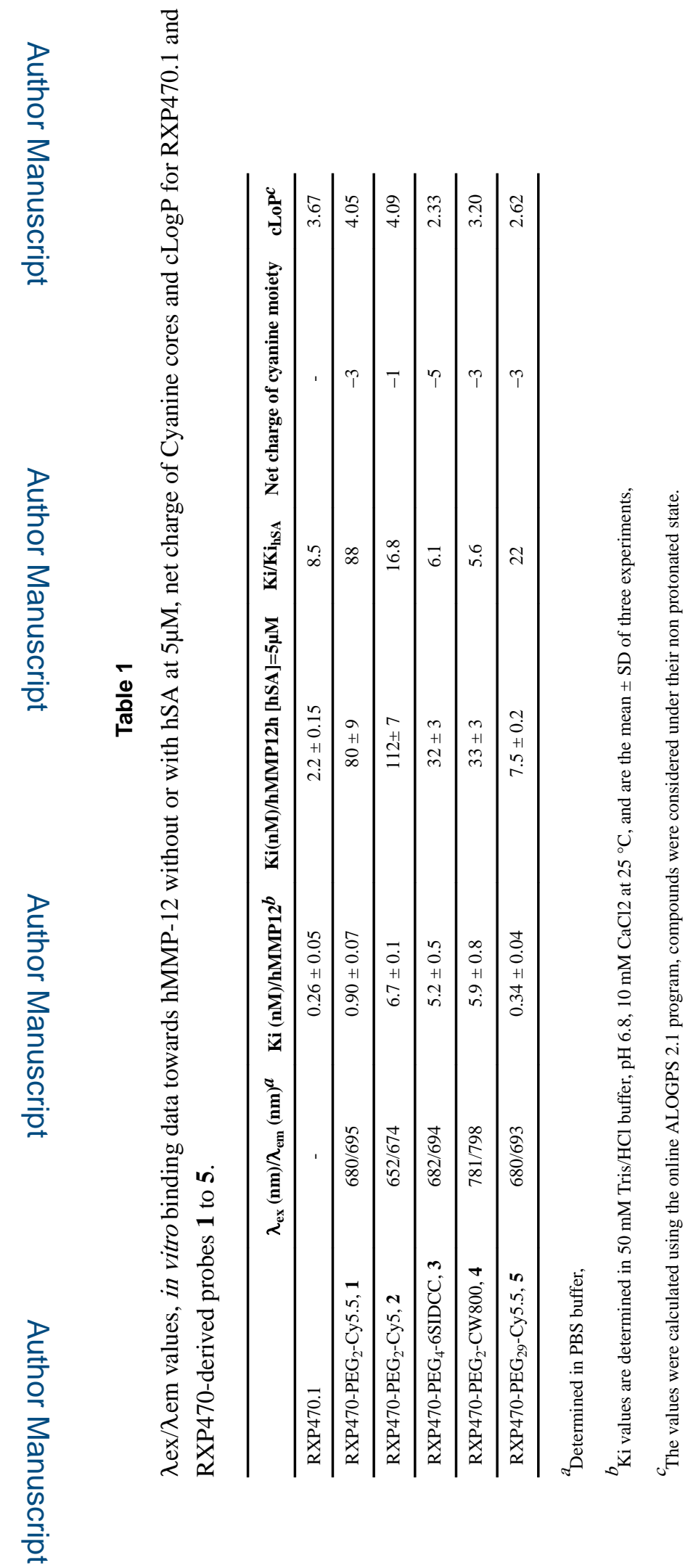

Bioconjug Chem. Author manuscript; available in PMC 2017 October 19. 